\title{
LA FRONTERA DE GRANADA A MEDIADOS DEL SIGLO XIV
}

\author{
Manuel GARCIA FERNANDEZ*
}

\section{INTRODUCCION}

El fenómeno singular y extraordinario que constituye la frontera de Granada ha sido un tema cargado de especial atractivo para los investigadores de la Historia Medieval de Andalucía (LADERO, M.A., 1976; CARRIAZO, J.M., 1974). Durante dos siglos y medio la existencia de esa frontera condicionó, explicó y justificó gran parte de la historia política, administrativa, institucional, socioeconómica, cultural, etc. de la región; hasta el punto de configurar la realidad histórica más importante del medievo andaluz. Porque, efectivamente, durante los siglos XIII al XV y frente a otros sectores de la Corona de Castilla Andalucía fue sobre todo tierra de frontera. Pero la frontera no sólo fue la zona de contacto y fricción entre cristianos y musulmanes sino también la ósmosis cultural de recíprocas influencias que dieron lugar a la génesis de fenómenos históricos e instituciones paralelas tanto en Andalucía como en el reino de Granada. Quizás por todo ello, la frontera no constituyó nunca un mundo cerrado e impenetrable, bien es cierto que diferenciaba dos modelos de civilización distinta, pero ¿tenían plena conciencia de ello los hombres que vivían a uno u otro lado? Creemos que no totalmente.

Por el contrario, parece más bien que desde su génesis en el siglo XIII la frontera se nos evidencia como un fenómeno singular, poco uniforme y homogéneo, y sobre todo sujeto a múltiples particularismos regionales, comarcales y locales. Cada reino, y prácticamente cada comarca geográfica, constituye una realidad fronteriza viva y distinta, que determina la existencia de una problemática específica, frente a la de otros sectores geográficos próximos e incluso vecinos. En este sentido, pues, el comportamiento de las tierras del Bajo y el Alto Guadalquivir no fue siempre idéntico, ni respondió a similares planteamientos fronterizos. Por ello, el estudio de este fenómeno en sus múltiples y diferentes facetas, manifestaciones y características presupone, sin duda, una gran dificultad; pues

(*) Profesor Titular Interino del Departamento de Historia Medieval. Universidad de Sevilla. 
en él inciden, de una u otra forma, todos los avatares históricos de los diferentes reinos andaluces en la Baja Edad Media. Ahora bien, estas pequeñas realidades fronterizas aisladas unas de otras muy poco significan, pero relacionadas entre sí nos revelan la existencia de ciertas líneas de comportamiento generales aplicables, no sin reservas, a toda la frontera de Granada, que es, en última instancia, lo que pretendemos.

\section{UNA APROXIMACION A LA FRONTERA GEOGRAFICA}

A lo largo de todo el siglo XIII, pero especialmente a mediados del mismo, las grandes conquistas militares llevadas a cabo por Fernando III y Alfonso X en el Valle del Guadalquivir, y sobre todo la paulatina y sistemática ocupación e integración de estas nuevas tierras a la Corona de Castilla, no sólo habían originado el "nacimiento de Andalucía" sino también el definitivo establecimiento del reino nazarí de Granada, teóricamente vasallo del castellano. Resultado de todo ello fue la existencia de una primera frontera entre ambos reinos; frontera que no sólo fue territorial y política sino cultural, lingüística, religiosa, etc. (GONZALEZ JIMENEZ, M., 1980; TORRES DELGADO, C., 1974). Esta primera frontera sufrió, evidentemente, diversas modificaciones durante los reinados de Sancho IV, Fernando IV y Alfonso XI. Pero a la muerte de este último monarca en 1350 la frontera de Granada fue paulatinamente encontrando ciertos cauces de estabilización y fijación geográfica que perduraron en líneas generales hasta el inicio de la Guerra de Granada a fines del siglo XV (MACKAY, A., 1981).

En cualquier caso, el análisis detallado de su ubicación geográfica resulta harto complejo (MARCHENA GOMEZ, M., 1987). Dos factores contribuyen principalmente a ello. En primer lugar, la inexistencia de una línea geográfica fronteriza, tal como la entendemos hoy, apoyada con precisión sobre accidentes naturales. En segundo lugar, la creciente movilidad fronteriza durante el reinado de Alfonso XI hasta 1344. Efectivamente, una extensa tierra de nadie despoblada, tanto en Granada como en Andalucía, y sometida a las acciones militares destructivas de los ejércitos castellanos y granadinos constituía lo qne podríamos llamar "la frontera viva y real" de los dos reinos. A niveles locales, cada pneblo, castillo o aldea, conocía perfectamente donde terminaba la jurisdicción de su propio territorio y donde comenzaba la del vecino más próximo al otro lado de la frontera. Pero, en la práctica, esta teórica delimitación apenas si era respeta$\mathrm{da}$; lo que ocasionaba mnchas veces graves fricciones fronterizas entre unos y otros. La existencia ocasional de algún accidente geográfico importante (ríos, montes, valles, etc.) contribuía a aclarar la delimitación de los respectivos términos fronterizos, pero cuando éste no existía, todo se dejaba al arbitrio de los "moros viejos sabidores" del lugar o de los "cristianos viejos" en su caso. 
Las conquistas del siglo XIV en la frontera de Granada complicaron el panorama ya existente, pues durante el reinado de Alfonso XI casi toda la frontera experimentó una notable remodelación desde las costas del litoral del Estrecho de Gibraltar hasta los montes de las Sierras Subbéticas de Jaén. En este sentido, la paulatina incorporación a la Corona de Castilla de nuevas plazas y castillos originaba una nueva restructuración de la frontera geográfica y la consiguiente apa* rición de estas áreas de dominio alterno y dudosa hegemonía. Más aún, en las diferentes treguas concertadas con Granada desde el siglo XIII aparecen una serie de cláusulas generales tendentes a la protección de estos vastos espacios vacíos como medida preventiva de seguridad en caso de agresión enemiga, mediante la prohibición de reedificar los castillos y las fortalezas más inmediata a la frontera tanto en Andalucía como en Granada.

La precariedad de las fuentes documentales conocidas al respecto, es compensada en parte por el Libro de la Montería de Alfonso XI, que constituye una excepcional fuente de información (CASARIEGO, J.E., 1976). En el mismo se documentan una serie de topónimos de todo tipo, pero especialmente de montes y serranías, que trasladados a un mapa de la región acaban por delimitar una auténtica frontera geográfica, pues significan los puntos más avanzados de control cristiano. De todas formas el Libro de la Montería presenta lagunas importantes ya que tan sólo nos documenta aquellas áreas fronterizas frecuentadas por el monarca en sus campañas militares o en sus expediciones cinegéticas por Andalucía. Con todo, se puede apreciar con relativa claridad una primera aproximación a la frontera castellano-nazarí a mediados del siglo XIV.

En efecto, la frontera geográfica debía arrancar en las proximidades de la costa del Estrecho de Gibraltar, en torno a la desembocadura del río Palmones, cuya posesión castellana era evidente tras la conquista de la ciudad de Algeciras en 1344; y del río Guadarranque, cuyo control era ya mucho más dudoso, especialmente tras la pérdida en 1333 de la plaza de Gibraltar y el fallido intento de su recuperación en 1350. La zona más occidental de la Bahía de Algeciras permaneció teóricamente bajo dominio cristiano hasta la destrucción de esta ciudad en 1369. A través del cauce de ambos ríos, la frontera ascendía hacia el norte por la Sierra de Montecoche. Una serie de cotas y cerros de mediana altitud, que aparecen controlados por Castilla desde fines del siglo XIII y citados en el Libro de la Montería como zona de cazaderos tradicionales de osos y ciervos, constituyen la frontera geográfica natural. Se trata de Puerto Yegua y Puerto Gáliz hasta el río Guadalete, ya en las estribaciones de Sierra Margarita. A esta altura, la frontera abandona paulatinamente la dirección norte para tomar una clara orientación este, paralela a las primeras estribaciones de la ladera más septentrional de la Sierra de Ronda, cuyas cotas de altitud quedan lejos del control cristiano. Su fijación no está documentada, tampoco el Libro de la Montería aporta datos topo- 
gráficos significativos. De todas formas, los castillos fronterizos de Zahara, Setenil y Ardales se sitúan con claridad en la órbita granadina; mientras que las plazas de Olvera, Pruna, Torre Alháquine, Otergícar, Las Cuevas y Teba constituían los puntos más avanzados de dominio castellano. Pero, de todos ellos, tan sólo Olvera y Teba eran plazas fuertes importantes de relativa seguridad; el resto no pasaban de ser simples torres fortificadas o castillos rurales aislados, dominados alternativamente por castellanos y granadinos durante los siglos XIV y XV. Sin embargo, ésta fue la zona geográfica de mayor penetración cristiana hasta 1410 , pues poblaciones granadinas como Ronda y Antequera quedaban tan sólo a pocos kilómetros de Olvera y Teba (Mapa I).

A la altura del cauce del río Guadalteba y del río Yeguas la frontera geográfica va a tomar, salvo raras excepciones, una constante dirección noreste. Efectivamente, por Los Llanos de Antequera y las Sierras del Humilladero se extiende una amplia tierra de control incierto hasta el río Genil. El libro de la Montería ofrece toda una serie de topónimos, perfectamente identificables hoy, que permiten ubicar la frontera al sur de Benamejí, Rute y Priego hasta Locubín y Alcalá la Real; por las Sierras de Halconera y Albayate, conquistadas y ocupadas hacia 1341; y también por la Sierra de Alta Coloma (Mapa II). Desde aquí continúa posiblemente por el valle del río Guadalbullón hasta las alturas de Sierra Mágina. Poblaciones como Torres, Cuadros, Bélmez, Jódar, Cabra del Santo Cristo, etc. permanecieron en poder de Castilla hasta el siglo XV; mientras que Huelma, Solera y otras estaban en poder de Granada. Más al norte, la frontera corre paralela al sur de las estribaciones de las agrestes Sierras de Segura y Cazorla penetrando en el territorio de Murcia. El Libro de la Montería guarda absoluto silencio sobre las tierras del Adelantamiento de Cazorla, señorío del arzobispo de Toledo (Mapa III).

\section{LA ESTRUCTURA DEFENSIVA DE LA FRONTERA DE GRANADA}

La existencia del reino de Granada no sólo motivó la aparición y consolidación de una frontera geográfica, sino que ocasionó la conversión de toda Andalucía en una auténtica tierra de frontera de la que, evidentemente, fueron conscientes los andaluces de la época. En este sentido, la frontera impulsó también la consolidación de un modelo singular de sociedad regional organizada para la guerra. Esta organización bélica se perfeccionó en tiempos de Alfonso XI mediante el establecimiento de un complejo sistema de fortificaciones, distribuidas por toda Andalucía, que respondía a una ordenación previa de la defensa territorial. Fortificaciones que presentan desde el siglo XIII unas peculiaridades propias que la determinan y caracterizan frente a otros sectores del reino. Tales peculiaridades 
vienen motivadas por las necesidades específicas de la Frontera. No se trata, evidentemente, de la construcción de un nuevo sistema de fortificaciones defensiva según los criterios coyunturales de cada momento histórico; sino más bien de consolidar un vasto sistema estructural ya latente en la región desde la conquista y ocupación del Valle del Guadalquivir. Ahora bien, en la organización del sistema los particularismos regionales, comarcales y locales tuvieron una especial relevancia. Cada reino, cada comarca o señorío, e incluso cada municipio, había organizado su propia defensa atendiendo a las necesidades, características, usos y costumbres del lugar, según lo había vivido y experimentado desde el siglo XIII. La diversidad geográfica regional acentuó también la existencia de tales particularismos locales; pues junto a las regiones llanas de las Campiñas aparecen casi sin continuidad otras zonas abruptas de difícil acceso en las Serranías Subbéticas. Naturalmente, la estructura defensiva de unas y de otras no podía ni debía ser idéntica. Por el contrario, sus edificaciones castrales variaron por este motivo en complejidad defensiva, distancia, profusión, materiales, etc. Así pues, los sistemas de fortificaciones andaluces del siglo XIV dependieron de factores como la tradición local, las necesidades particulares de cada sector fronterizo, el grado de ocupación del territorio, la orografía, la poliorcética, etc. Sin embargo, a nivel de toda Andalucía se detecta desde el siglo XIII la existencia de un complicado sistema estructural defensivo, organizado mediante la articulación de dos líneas de construcciones castrales y otra tercera de ciudades y villas bases con fines logísticos que se escalonan desde la margen izquierda del río Guadalquivir hasta las primeras estribaciones de los montes del Sistema Subbético y el Estrecho de Gibraltar.

Las tierras más inmediatas a la Vega del río Guadalquivir configuraban la tercera línea defensiva y los centros de apoyo logísticos de la región. Esta zona era la más alejada de la frontera geográfica; lo que garantizaba en gran medida su relativa seguridad, propiciando una mayor densidad de población y mayor abundancia de recursos. Importantes ciudades como Sevilla, Córdoba y en menor medida Jaén se habían convertido desde fines del siglo XIII en auténticas ciudadesbases de hombres, recursos y pertrechos en la defensa de sus respectivos reinos; ya que únicamente en ocasiones muy especiales de extrema gravedad y peligro unificaban sus esfuerzos.

Pero la complejidad defensiva de algunas áreas geográficas alejadas de estos grandes centros logísticos de Andalucía hizo resaltar cada vez más la importancia estratégica de otros núcleos de población de menor entidad urbana, pero mucho más cercanos a la frontera. De modo que, a lo largo de la primera mitad del siglo XIV, estos núcleos de población favorecieron la génesis de un entramado defensivo y logístico constituido por pequeñas ciudades y villas bases fronterizas, que alternaban su primitiva misión de enclave fortificado ofensivo-defensivo con otras funciones de organización, almacenaje y aprovisionamiento de recursos y 
pertrechos para otros núcleos fronterizos más avanzados y distantes de las grandes ciudades del Valle del Guadalquivir. En este sentido, en la difícil área del río Guadalete, duramente castigada por las razzias de los benimerines desde 1275 , se destacó la ciudad de Jerez de la Frontera, paso obligado para todos los ejércitos cristianos que bajaban a la defensa de la frontera del Estrecho de Gibraltar. Asímismo, en la Campiña de Sevilla y Córdoba, trágicamente saqueada por las algarás de los granadinos, desde el siglo XIII resaltó la importancia estratégica de Carmona y, sobre todo, de Ecija; los baluartes defensivos y logísticos más importantes de la comarca. Por último, en el Alto Guadalquivir, actuaron también en este sentido las poblaciones de Ubeda y Baeza y en menor medida Arjona, si bien se encontraban un poco más retiradas de la frontera geográfica que las primeras (Mapas I, II y III ) (FERIA TORIBIO, J.M., 1984).

La segunda línea defensiva estaba constituida por un complejo entramado de castillos que formaban parte de un conjunto de fortificaciones, aIcázares, alcazabas, cercas, murallas y torres, con autonomía suficiente para resistir en caso de peligro durante algún tiempo (COLLANTES DE TERAN, Fr., 1953). Se trataba de poblaciones rurales situadas por lo general en las inmediaciones de los antiguos pasos y caminos; dominando las vías de acceso y penetración desde Granada a Andalucía y apoyándose mútuamente desde sus respectivas atalayas y oteros sobre los que se erigen como baluartes defensivos. Otras veces, aparecen ubicadas a la sombra protectora de los montes Subbéticos del Alto Guadalquivir; o escondidas en los profundos valles de los ríos que defienden; o elevadas sobre las pequeñas lomas de las campiñas que protegen. En todo caso, su situación fue siempre muy estratégica y de segura defensa ante posibles ataques granadinos. Su importancia fue muy considerable durante los siglos XIV y XV porque constituían la primera resistencia sería en caso de agresión enemiga. Así que sufrieron frecuentes cercos y sitios durante la Baja Edad Media. De su cruda y difícil supervivencia diaria fueron conscientes los propios contemporáneos, especialmente la Corona, que decretó toda una serie de medidas tendentes a conseguir su definitiva consolidación como enclaves fronterizos de gran relevancia defensiva en áreas de especial conflictividad.

En efecto, la situación poblacional deficitaria de las tierras del Estrecho y del río Guadalete, paso obligado de los ejércitos norteafricanos hacia el interior de la Baja Andalucía, obligó a la Corona a promocionar el poblamiento de esta segunda línea defensiva cuyos núcleos más importantes del litoral eran los de Tarifa, Algeciras y Gibraltar. Más al interior estaban las plazas fuertes de Alcalá de los Gazules, Medina Sidonia y Arcos de la Frontera, que cerraban por el sur las vías de penetración hacia Jerez de la Frontera. En las primeras estribaciones del Sistema Subbético destacaban las plazas de Olvera, Teba y Cañete la Real que cerraban los pasos desde Ronda y Antequera. Del mismo modo, en las áreas geográficas colindantes a la Campiña de Sevilla y Córdoba, resaltaban núcleos forti- 
ficados de especial interés ya desde el siglo XIII como los de Morón de la Frontera, Estepa, Osuna y La Puebla de Cazalla que defendían el camino hacia Ecija y Carmona (Mapa I). Por su parte en el reino de Córdoba encontramos con misiones similares a las plazas de Cabra, Luque, Priego y sobre todo Aguilar de la Frontera (Mapa II). Mientras que en las tierras del Alto Guadalquivir esta segunda línea de fortificaciones defensivas quedaba representada por la plaza de Alcalá la Real y por los castillos de Martos, Cazorla, Segura, Jódar y Bédmar (Mapa III).

Por último, la primera línea defensiva estaba integrada por un sin fin de pequeñas edificaciones castrales (torres, castillos rurales, atalayas, etc.) distribuidas por toda la frontera. Muchas de ellas no son, evidentemente, fortificaciones inmediatamente fronterizas; por el contrario, aparecen ubicadas más al interior configurando una especie de cinturón fortificado, visible y bien comunicado, en torno a los núcleos defensivos más relevantes de segunda línea anteriormente estudiados. Se trataba, por tanto, de fortificaciones aislada, con una organización más o menos compleja y que, al menos teóricamente, se bastaban para su autodefensa. Era el caso de los castillos de Torre Estrella, Gigonza, Tempul, Matrera, Las Aguzaderas, Cote, etc. en el reino de Sevilla. Así como los de Rute, Benamejí, Carcabuey, etc. en el reino de Córdoba. Y también los de Locubín, Albánchez, Tíscar, etc. en el reino de Jaén.

Por último este vasto sistema defensivo, articulado mediante estas tres líneas de fortificaciones, se organizaba atendiendo a dos modelos estructurales, uno general y otro radial.

La estructura paralela general se basaba en la mera yuxtaposición arbitraria de las tres líneas fortificadas, que descienden escalonadamente desde el Valle del Guadalquivir hasta las primeras estribaciones de los montes Subbéticos. Por su parte, la estructura radial regional se basaba en un tipo de organización defensiva que atendía principalmente a las necesidades específicas de cada uno de los tres reinos andaluces. Por lo que cada sector se encargó de su respectiva frontera, actuando como cabecera del mismo la capital del reino: Sevilla, Córdoba y Jaén. Se pretendía, pues, con todo ello un auxilio mucho más rápido y eficaz habida cuenta las fricciones cotidianas, dejando únicamente para ocasiones muy excepcionales la unificación de los esfuerzos de los tres reinos andaluces. A lo largo de los siglos XIV y XV se impuso esta organización radial de la defensa de la frontera; lo que determinó la aparición de grandes marcas fronterizas regionales e incluso comarcales con caracteres geográfico-defensivos propios (FERIA TORIBIO, J., 1984). 


\section{TRES REINOS FRONTERIZOS}

Como ya hemos apuntado más arriba, bajo el término genérico de la Frontera, sin más apelativos, se agrupaba desde el siglo XIII a todas las tierras y a todos Ios hombres del Valle del Guadalquivir. Sin embargo, esta pretendida unidad andaluza en torno a la Frontera tan sólo era entendida, comprendida y vivida a niveles teóricos por los propios andaluces, quienes se sabían y sentían unidos por vínculos comunes, distintos y superiores a su pertenencia al reino de Castilla; una misma historia, una misma estructura social y económica, unos mismos intereses y una misma mentalidad: saberse hombres de frontera.

Pero a niveles pragmáticos (fiscales, judiciales, militares, gubernativos y administrativos) Andalucía aparece fragmentada también desde el siglo XIII. Pues, a pesar de que ciertas instituciones se identificaron con todo o con parte del espacio geográfico andaluz, tales como el Adelantamiento, el Almirantazgo, las Ordenes Militares, la Iglesia, etc. , la Corona no respetó en modo alguno la "pretendida unidad regional". Por el contrario, los monarcas bajomedievales continuaron titulándose reyes de Sevilla, de Córdoba, de Jaén y casi nunca de Andalucía, como lo eran de Castilla, de León, de Galicia (CANO GARCIA, G., 1987). En efecto, la división político-administrativa de Andalucía en tres reinos: Sevilla, Córdoba y Jaén se nos muestra ya perfectamente consolidada a mediados del siglo XIV. Factores de muy diversa índole explican y determinan este fenómeno regional andaluz que, sin embargo, nunca originó la aparición de sevillanos, cordobeses y jienenses. Entre ellos debemos destacar, principalmente, los aspectos relacionados con la defensa de la frontera (GONZALEZ JIMENEZ, M., 1980).

En este sentido, desde el siglo XIII cada uno de los tres reinos andaluces se venía ocupando de su propia autodefensa según los esquemas de marcas fronterizas y líneas de fortificaciones analizados más arriba. En virtud del mismo, era prácticamente las grandes ciudades de realengo del Valle del Guadalquivir las que podían garantizar eficazmente la defensa de la región. Por ello, en alguna medida, los reinos andaluces nacen de la misma parcelación de la frontera, cuya defensa se confía a sus concejos coordinados y apoyados por y desde la cabecera del reino respectivo. A mediados del siglo XIV y en general durante la Baja Edad Media este será un hecho perfectamente asumido y aceptado por todos los andaluces.

Por otra parte, la cronología del proceso conquistador del siglo XIII había determinado también la gestión de esta triple fragmentación administrativa y territorial; sus consecuencias continuaron vigentes hasta el final de la Edad Media. Por ello, las poblaciones conquistadas durante estos años de mútua frontera castellano-nazarí se englobaron y vincularon a la órbita político-administrativa de los reinos próximos tal como había ocurrido en el siglo XIII. Así, por ejemplo, las plazas de Olvera, Teba, Gibraltar, Castellar de la Frontera, Antequera, etc. 
lo fueron al de Sevilla, repitiendo la organización y problemática general del reino hispalense; mientras que las de Benamejí, Priego, Rute, etc. lo fueron al de Córdoba y las de Alcalá la Real, Tíscar, Huelma, Solera, etc. lo fueron al de Jaén (CANO GARCIA, G., 1987).

A estos aspectos militares y fronterizos debemos sumar también los de carácter fiscal, judicial, administrativos, etc. si queremos completar el cuadro de las causas que explican, a nuestro modo de ver, la fragmentación andaluza en tres reinos y el relativo fracaso de la unidad regional. Más aún, los grandes municipios del Valle del Guadalquivir se habían constituido, al menos ya desde el siglo XIV, en auténticos centros de gobernación no sólo de asuntos militares y defensivos sino también fiscales y judiciales de sus respectivos reinos. Cada uno de ellos presentó muchas veces una problemática distinta a la de los reinos vecinos. Este hecho determinó la aparición de un marcado localismo, especialmente judicial y administrativo, que la Corona intentó superar mediante un desarrollo legislativo sin precedente en tiempos de Alfonso XI. Que se lograse o no es, evidentemente, otro problema. Sin embargo, no podemos dudar del gran esfuerzo realizado en este sentido por la administración central.

De todas formas, las diferencias regionales andaluzas no podían enmascarar y de hecho nunca lo consiguieron del todo, la existencia de unas estructuras socioeconómicas que respondían, dentro de sus peculiaridades, a un modelo de organización similar y en muchos aspectos distinto al resto del reino de Castilla. La existencia de la frontera con Granada determinó la gestación de ciertas características unitarias entre los andaluces, siempre a niveles ideológicos; historia, cultura, mentalidad, etc. Porque a niveles prácticos, fiscales, administrativos, judiciales, etc. y sobre todo defensivos la frontera provocó la paulatina parcelación de Andalucía en tres reinos, cuyos ejes centrales lo constituían respectivamente las grandes ciudades de Sevilla, Córdoba y Jaén (Mapa IV).

\section{LA GUERRA Y LA PAZ Y SU REPERCUSION EN LA FRONTERA DE GRANADA}

Por todo ello, resulta evidente, pues, que desde el siglo XIII el reino nazarí de Granada se convirtió en el contrapunto más importante de la política exterior de la Corona de Castilla en Andalucía. Las relaciones entre ambos reinos se manifestaron, ya desde entonces, en una doble vertiente institucionalizada a través de la guerra y de la tregua en la frontera. Pero tanto una como presentaron sus propias earacterísticas, muchas veces distintas y ajenas a las del resto del reino. Porque en la frontera de Granada ni la paz ni la guerra fueron hechos rotundos ni completamente aceptados y respetados por todos los hombres que vivían a ambos lados de la frontera. Por el contrario, ni la tregua fue la paz absoluta ni la guerra fue nunca la destrucción total. 
Efectivamente, la guerra no fue nunca la lucha ciega de toda Andalucía frente a Granada sino que dependió, en gran medida, de múltiples particularismos locales, no ya sólo de cada reino sino incluso de cada comarca fronteriza. Por lo que a acciones militares emprendidas por los andaluces y granadinos en un sector determinado de la frontera podían corresponder, y de hecho correspondieron, etapas de relaciones más o menos pacíficas llevadas a cabo en otras áreas fronterizas próximas o vecinas. Esta fue una situación típica de la frontera granadina, distinta y única, frente a las otras fronteras de los reinos peninsulares durante la Baja Edad Media. En este mismo sentido, la tregua no significó jamás la paz, ni mucho menos la absoluta interrupción a nivel general de toda Andalucía de las operaciones bélicas. La guerra y la paz dependieron en la Frontera de la existencia de realidades peculiares y distintas en cada reino y comarca. Se trataba, más bien de un estado de guerra y paz atenuada, propiciada por múltiples problemas internos, motivados a su vez por la presencia ya desde el siglo XIII de varias realidades fronterizas. Por tanto, no fueron nunca asuntos exclusivos de los Estados y los Monarcas, sino también negocios particulares de los hombres de la frontera. Cada uno, pues, entendió y realizó "su guerra" y "su paz" a su antojo. Todo ello proporcionó a estas dos instituciones fronterizas ciertos caracteres de arbitrariedad y de alto riesgo cotidiano debido, principalmente, al libre albedrío de unos y de otros, de cristianos y musulmanes, muchas veces no comprendido ni aceptado por el resto de los hombres del reino de Castilla. De modo que la frontera originó una forma peculiar de comprender y hacer la guerra. Peculiaridades que en modo alguno fueron totalmente innovadoras sino que se fundamentaban en la tradición y experiencia de más de cuatro siglos de guerras de frontera y sobre todo en el empirismo de la vida cotidiana a ambos lados de la misma.

Frente a las guerras, las treguas continuaron siendo al menos teóricamente la otra cara de la moneda. Treguas mejor que paces, pues la interrupción de las operaciones bélicas no fue un hecho aceptado por todos los andaluces. Por el contrario, dependió siempre de la existencia de múltiples realidades fronterizas geográficas y distintas. La restitución del tráfico comercial, la indemnización de los daños de guerra, etc., ocasionaron a su vez agresiones locales en amplios sectores de la frontera que llegaron incluso a quebrantar la paz general o a ponerla en serio peligro. Más aún, aprovechando esta coyuntura de relajación militar renacían las revanchas, los antagonismos fronterizos, los odios religiosos integrales, que obligaban a unos y a otros — cristianos y musulmanes, andaluces y granadinos - a emprender de nuevo acciones militares de castigo en las poblaciones vecinas; lo que originaba a su vez múltiples querellas, desagravios, etc. Porque, efectivamente, la tregua no podía ser jamás la paz absoluta en una frontera que estaba destinada a desaparecer en cualquier momento, fenómeno del que eran conscientes los propios contemporáneos, especialmente los granadinos. De todas formas y a pesar de esta difícil dinámica, las treguas establecieron en la fron- 
tera, a niveles generales, ciertos cauces de convivencia entre cristianos y musulmanes, con independencia de posibles agresiones locales. En este sentido y según ya hemos apuntado más arriba, las diferentes treguas reactivaron algunas iniciativas comerciales, favorecieron el mútuo rescate de los cautivos, negocio interesantísimo que monopolizaban los alfaqueques, solventaron problemas de términos; en una palabra se "racionalizaba" la vida de la frontera. La Corona puso especial interés en estos aspectos mediante el establecimiento de "alcaldes de moros y cristianos" con la intención de evitar robos, refugio de malhechores y dirimir pleitos entre vecinos fronterizos condenados a entenderse en la convivencia diaria (TORRES FONTES, J., 1960 y 1975).

\section{CONCLUSIONES}

A la hora de concluir este trabajo debemos confesar que todo lo analizado tan sólo constituye unas breves pinceladas, ligeros apuntes de carácter general, del complejo mundo de la frontera de Granada, cuyo estudio sobrepasa las limitaciones impuestas:

1. La frontera de Granada constituye, sin duda, el eje central de la Historia Medieval de Andalucía. Es más, gran parte de la región se convirtió ya desde el siglo XIII en una auténtica "marca fronteriza". Esta situación explica y condiciona muchos de los caracteres específicos de la Andalucía actual tales como hábitat y poblamiento concentrado, economía agraria y latifundios, administración municipal, sociedad aristocrática, etc. (Mapa IV) (GONZALEZ JIMENEZ, M., 1980). Así mismo, la frontera fue también la ósmosis cultural de recíprocas influencias regionales en instituciones fronterizas (alfaqueques, alcaldes de moros y cristianos, fieles del rastro), pero sobre todo en la vida cotidiana de los andaluces que vivían a ambos lados de la misma.

2. El reinado de Alfonso XI de Castilla constituye un período clave para el estudio del fenómeno fronterizo en sus múltiples y variadas facetas en Andalucía. En efecto, en su tiempo (1312-1350) la frontera geográfica encuentra ciertos cauces de fijación que van a perdurar hasta el inicio de la guerra de Granada en 1482. Asímismo se consolidan definitivamente los entramados estructurales de fortificaciones defensivas de carácter ubano, fundamentalmente para entender el actual sistema de ciudades medias y sus áreas de influencia en Andalucía (Mapa V) (FERIA TORIBIO, J., 1984). 
A modo de justificación tenemos que afirmar que la línea directora del mismo ha sido siempre la búsqueda de una visión de conjunto regional de fenómenos particulares de prolija explicación local. De los mismos hemos resaltado los aspectos que más podrían interesar al posible lector de la Revista de Estudios Andaluces; es decir, aquellos relacionados con la geografía física y humana de la frontera de Granada y sus instituciones. Y lo hemos hecho desde la perspectiva que imponen las fuentes cristianas, desde la Andalucía Bética; pues más allá de la frontera, el resto del territorio que configuraba el reino de Granada nunca tuvo para los contemporáneos de los siglos XIII al XV la identificación regional que hoy justamente le asignamos.

\section{BIBLIOGRAFIA CITADA}

CANO GARCIA, G.: Geografía de Andalucía. Edt. Tartessos. "Evolución de los límites de Andalucía y percepción del territorio". Sevilla, 1987. Tomo I.

CARRIAZO, J.M.: En la Frontera de Granada. Sevilla, 1974.

CASARIEGO, J.E.: Libro de la Montería de Alfonso XI de Castilla. Madrid, 1976, II Tomos (B.C.E., según la versión de Gutiérrez de la Vega de 1877).

COLLANTES DE TERAN Y DELORME, Kr.: "Los Castillos del reino de Sevilla", Archivo Hispalense, T. XVIII, n. ${ }^{\circ}$ 58-59 (1953), pp. 117-185.

FERIA TORIBIO, J.M. ${ }^{a}$ : "El sistema urbano andaluz; cuestiones metodológicas y problemas de información". Revista de Estudios Andaluces, n. ${ }^{\circ} 3$ (1984), pp. 125-144.

GONZALEZ JIMENEZ, M.: En torno a los orígenes de Andalucía, Sevilla, 1980.

- Historia de Andalucía. "La Andalucía Dividida (1081-1350)". Barcelona, 1980, T. II. Ed. Planeta.

LADERO QUESADA, M.A.: "La investigación histórica sobre Andalucía Medieval, en los últimos veinticinco años (1951-1976). Actas del I Congreso de Historia de Andalucía. Andalucía Medieval. (Córdoba, 1976), pp. 243-245.

MACKAY, Ag.: La España de la Edad Media. Desde la frontera hasta el imperio 1000-1500. Madrid, 1981.

MARCHENA GOMEZ, M.: Geografia de Andalucía, (Director: G. CANO). "La imagen geográfica de Andalucía”. Edt. Tartessos. Sevilla, 1987. T. I.

TORRES DELGADO, C.: El antiguo reino nazari de Granada 1232-1350. Granada, 1974.

TORRES FONTES, J.: "El alcalde de moros y cristianos en el reino de Murcia”. Hispania, T. XX, n. ${ }^{\circ} 78,(1960)$, pp. 55-80.

T. II, (1975), pp. 99-116. 


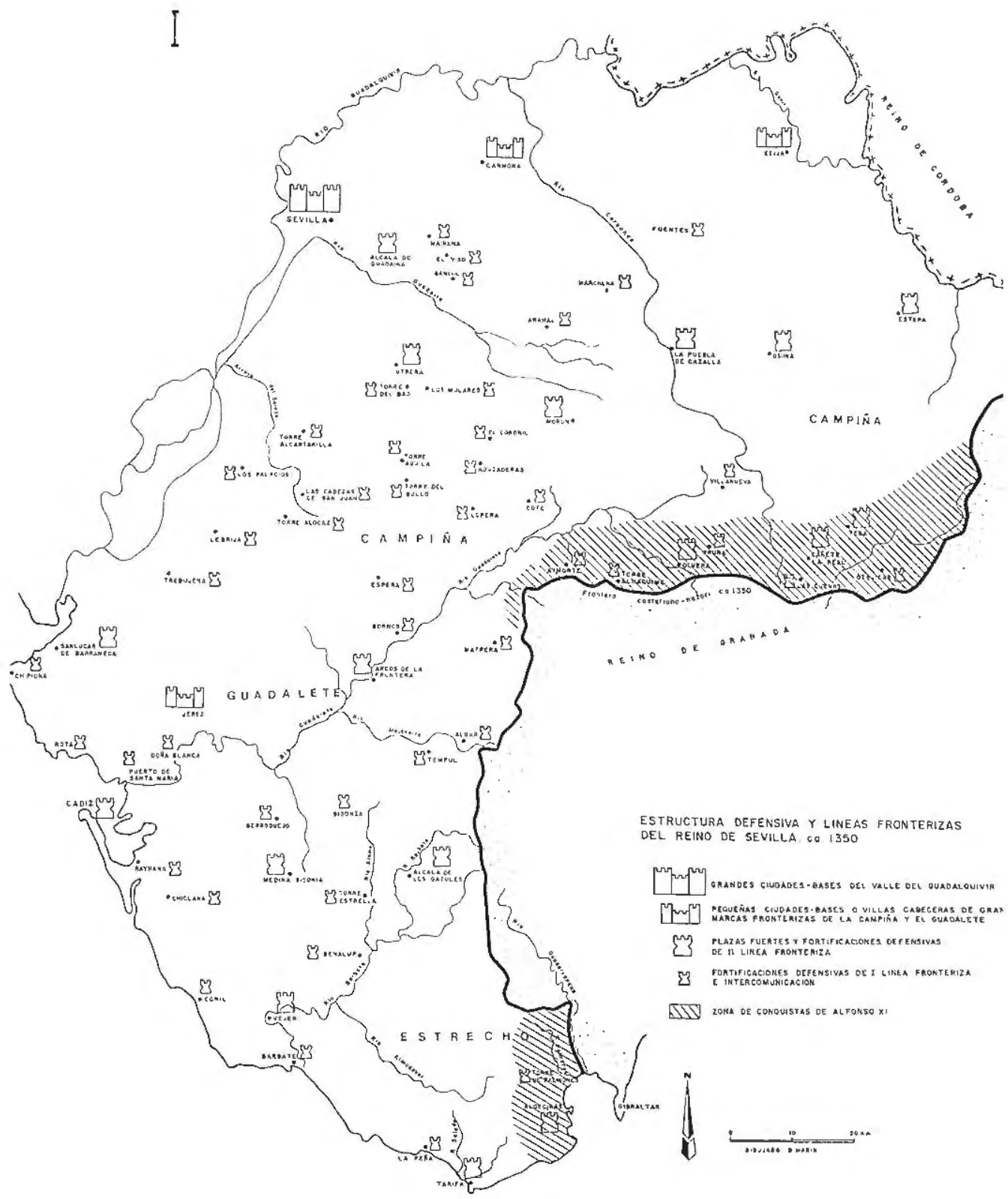




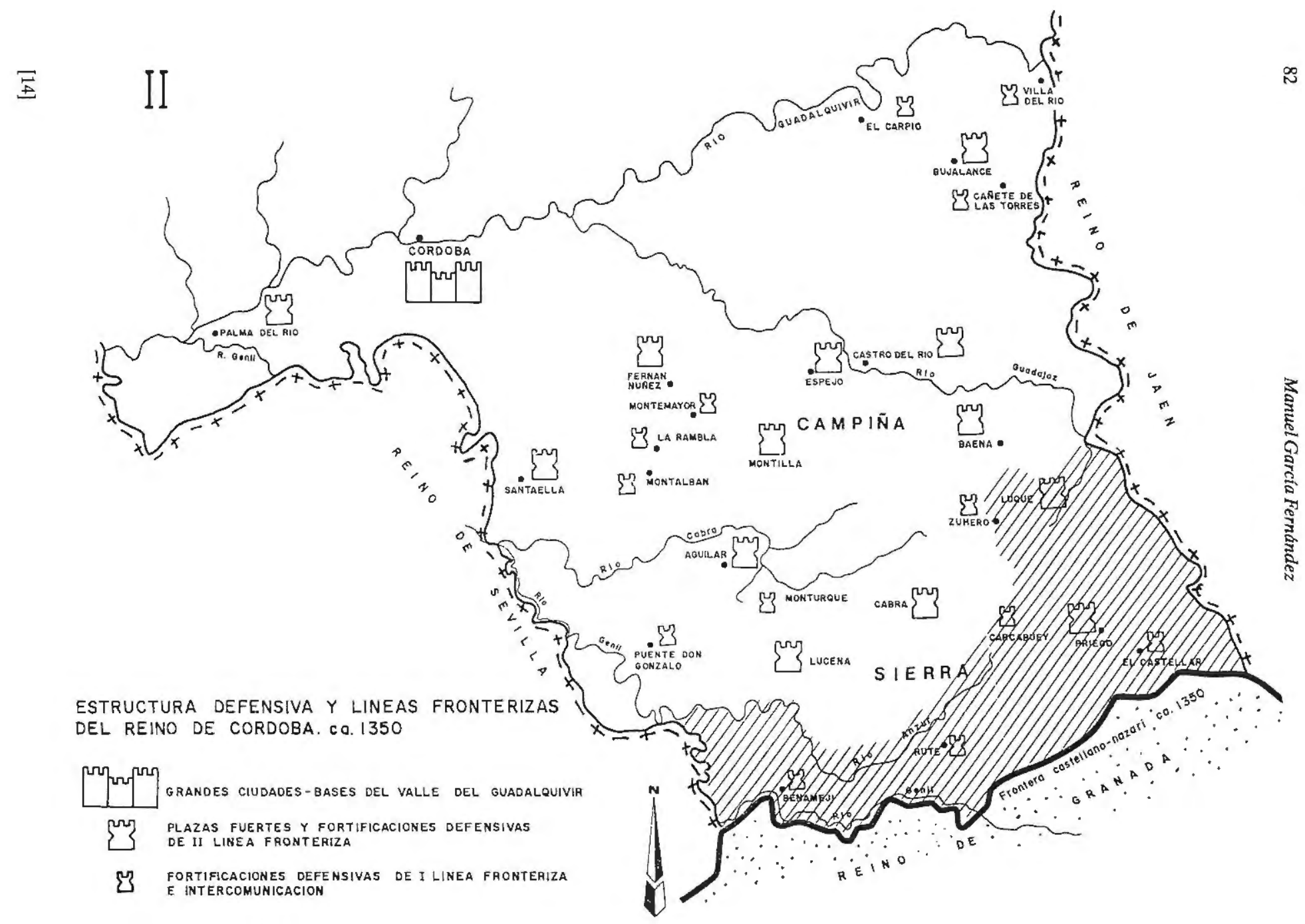




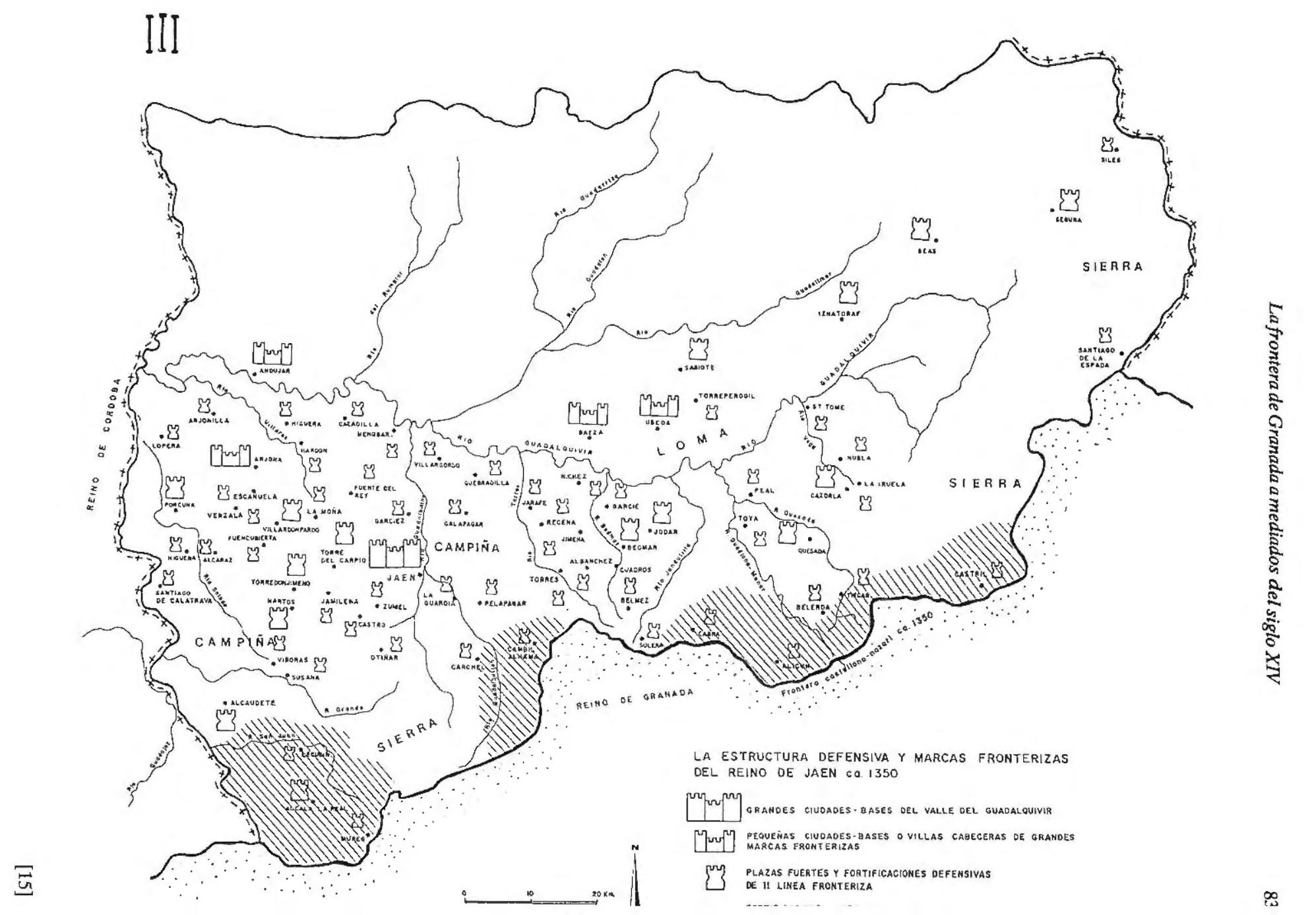




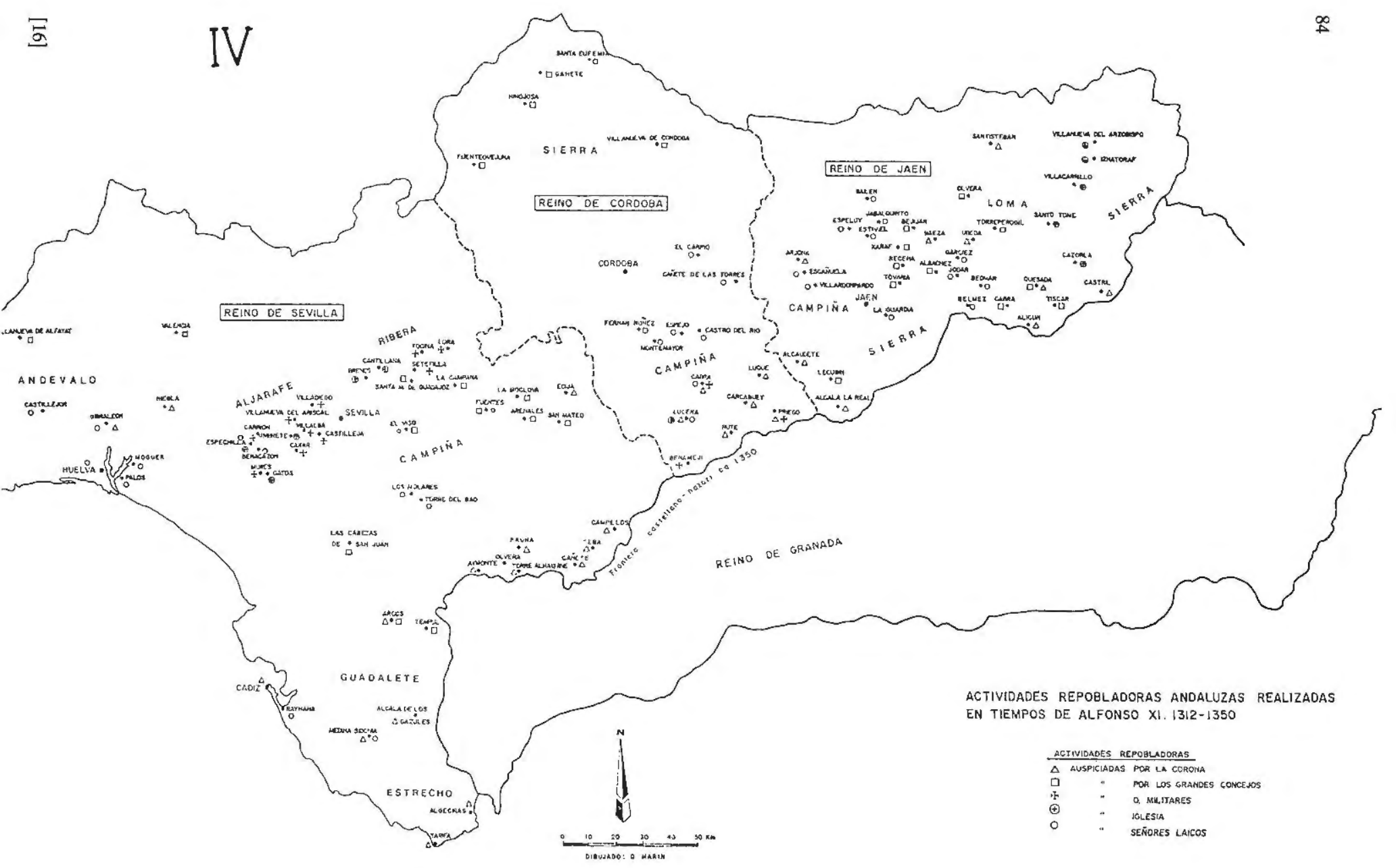




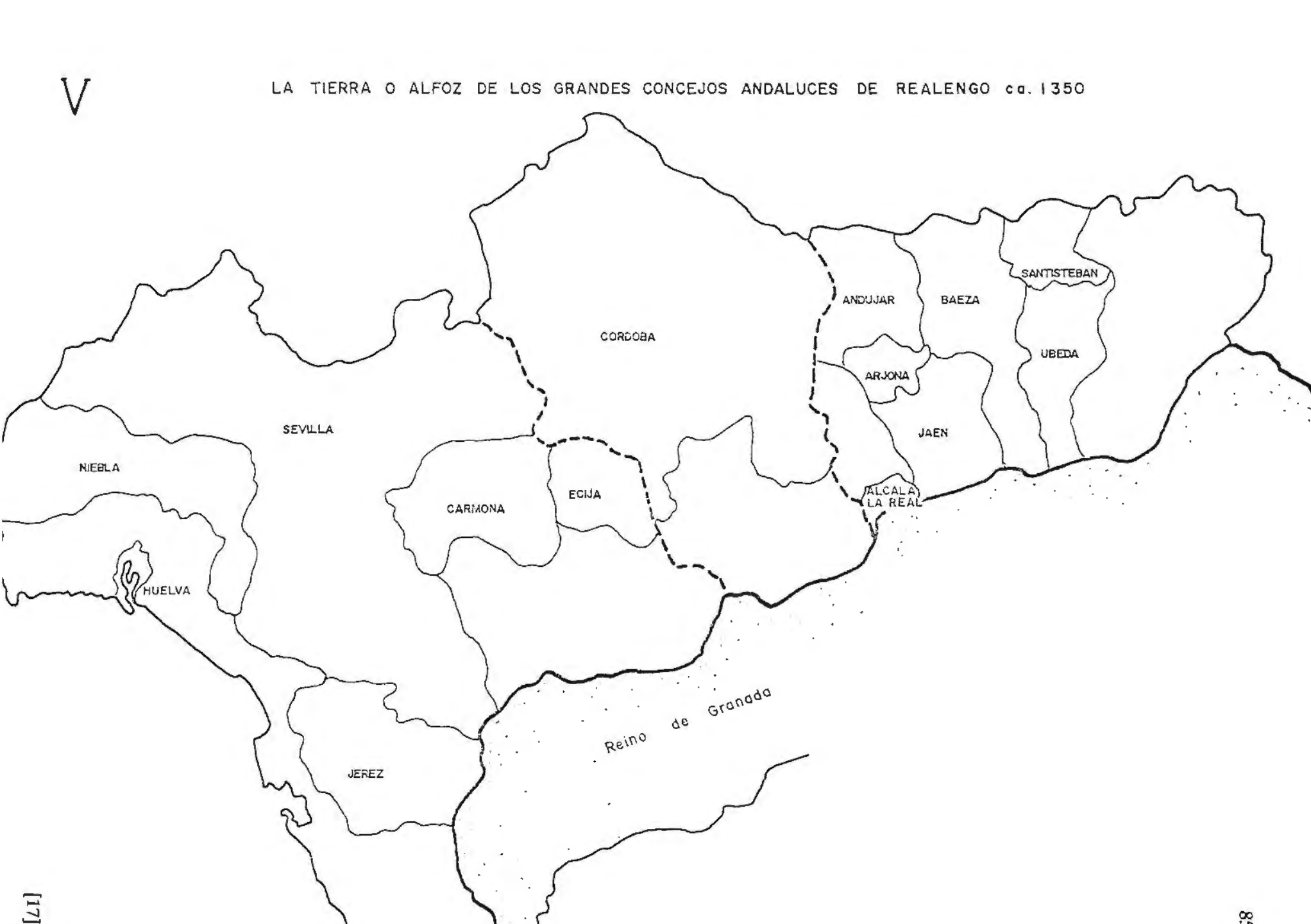

